\title{
A Scrutiny on the Burnout Levels of Fencing Referees
}

\author{
Yusuf BARSBUĞA' ${ }^{1}$ İbrahim BACAK, Tuncay Sarıipek \\ ${ }^{1}$ Selcuk University, Faculty of Sport Sciences, Department of Sports Management. Konya/TURKEY.
}

\begin{abstract}
The objective of this study is to measure and interpret the burnout levels of the fencing referees who act in the fencing contests in our country as referees actively. The study group is constituted by the 60 referees with varying refereeing levels taking place on the Certified Referees List 2018 of the Turkish Fencing Federation. The Maslach Burnout Inventory developed by Maslach and Jackson (1981) and adapted into Turkish conducting a study on its reliability and validity by Ergin (1992) was used in this study conducted on the basis of the survey model. In the evaluation of the data and determination of the calculated values, SPSS 16.0 statistics package program was used. The data was summarized by providing the percentages, averages, and standard deviations. As the data distributed normally, an independent group $t$ test was used for the pairwise cluster comparisons and One Way Variance Analysis (ANOVA) was used for the multiple cluster comparisons. Tukey HSD multiple comparison test was conducted to determine the significant differences as a result of the ANOVA. The scale reliability coefficient was calculated as .82 and significance level was taken into account as 0.05 in this study. In conclusion, it was observed that the variables of ages, income and education statuses, sportsperson ship background, and material revenues obtained from acting as referees did not differentiate statistically and statistically significant differences were determined in terms of the variables of refereeing experience period, refereeing level, and the number of the annually received assignments, in the personal success subcategory.
\end{abstract}

Keywords: Sport, Fencing, Referee, Burnout 